\title{
THE WESTERN PACIFIC AND MAGMA GENESIS
}

by

Kenzo Yagi

The International Geodynamics Conference, organized by one of IUGS' joint programs - the Inter-Union Commission on Geodynamics (ICG), convened two ICG working groups in Japan in March - "Geodynamics of the Western Pacific Indonesian Region" (Working Group l) and "Properties and Processes in the Earth's Interior" (Working Group 5). Their activities have contributed much in extending and modifying plate tectonic models by both elucidating the tectonics of various regions and establishing physical-chemical mechanisms for basic geological processes. Professor Yagi, one of the Conference convenors, reports on the scientific achievements of the Conference and its successful field excursion to the volcanoes of the Izu-Hakone District and Oshima Island.

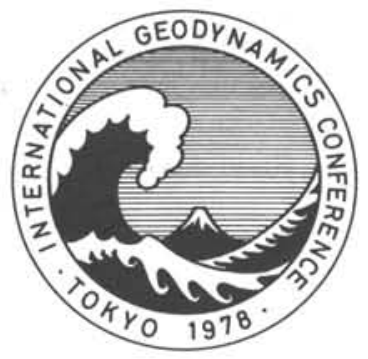

Symbol of the Conference: designed after the famous picture of Mt. Fuji by Hokusai Katsushika, a famous Japanese artist (1760-l849), the waves represent "the Western Pacific", while Mt. Fuji is a product of "Magma Genesis".

Introduction

The Japanese Islands have a particular geographical advantage over other locations in the study of several principal subjects in geodynamics. They form typical island arcs, located on the northwestern rim of the Pacific Ocean, underlain by an active subduction zone which generates earthquakes and volcanic eruptions. In view of this, ICG's Working Groups 1 and 5 decided to establish the following major aspects of geodynamic investigations as the themes for the International Geodynamic Conference: tectonics of the Western Pacific, and, the physics and chemistry of magma genesis. Held in Tokyo at the Science Council of Japan from March 13-17, 1978 and supported financially by the Ministry of Education, Science and Culture, the Conference was co-sponsored by IUGS' Commission on Experimental Petrology at High Pressures and Temperatures and several other international associations. About 200 Japanese scientists joined the 80 or so foreign participants from 19 countries.

The two invited papers followed the Conference's opening address. W.R. Dickinson of Stanford University, ("Plate tectonic evolution of North Pacific rim") discussed the major types of tectonic events that have affected the Pacific rim since the Mesozoic breakup of Pangaea, and suggested how some problems could be tackled by studying the remnants of Precambrian terrain, the inferred Paleozoic sea floor, and Paleozoic terrain. H.S. Yoder, Jr. described basic magma generation and aggregation by presenting numerous experimental data to support production of basaltic magma from garnet periodotite under eutectic-like conditions. He extended this to propose the "hot plate" method of magma generation as opposed to the diapiric process. These papers were followed by the lectures of S.A. Fedotor and Y. Katsui on basaltic and dacitic volcanism and illustrated by movies of the 1975-76 eruption of Tolbachik, Kamchatka, and the 1977 eruption of Usu, Japan. Altogether, 185 papers were presented at the Conference.

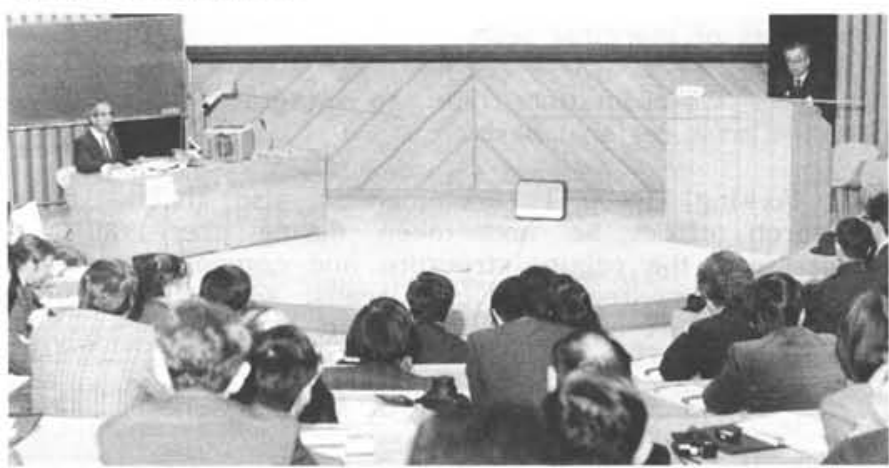

Welcoming address is delivered by Professor T. Asada, Chairman of the Local Organizing Committee, with Professor Kenzo Yagi presiding over the opening meeting at the Science Council of Japan (photo courtesy Asahi Evening News Press).

\section{Geodynamics of the Western Pacific-Indonesian Region}

A major subject of the first part of the Conference was the origin and evolutionary history of marginal seas. Three papers dealt with the present and past features of the Japan and Okhotsk Seas, while five papers dealt with regional geology and geophysics of the northern Philippine Sea region (the Shikoku Basin, Daito Ridge and Kyushu-Palau Ridge). Tectonic settings of the Fiji Basin and the Coral and Andaman Sea Basins were also reported on by several institutions and evidence for the remnant marginal basins in the Southern Andes was reviewed.

Several hypotheses on formation of marginal or back-arc basins were postulated and discussed. Stress distribution at the time of formation of a basin was considered to be the best clue as to the most likely 
mechanism of formation. Volcanological evidence for the nature of stress in arc and back-arc regions was presented with the hope that future accumulation of such field evidence, from widely separate areas in various stages of evolution, combined with geophysical observations in the actively opening zones, will contribute to solving this problem.

A workshop on the origin of marginal seas issued a resolution to recommend specific studies of dynamic processes of active and formerly active areas, grouped into the following five categories:

I. Dynamic processes of active areas: 1) OBS studies of spreading centers and subduction zone; 2) earth tide measurements; 3) stress measurements; 4) utilization of strainmeter and tiltmeter observations.

II. Mapping projects: 1) use of aerial surveys for magnetic anomaly studies; 2) dredging surveys to obtain widespread sampling; 3) IPOD drilling; 4) detailed bathymetric mapping; 5) extended network of refraction lines; 6) greatly amplified paleomagnetic studies; 7) radiometric age dating; 8) use of submersibles.

III. Model studies: 1) elaborated model studies as a guide to field projects; 2) alternate models to convection; 3) modelling of cases where subduction zones have no back-arc basins; 4) complete stacking of magnetic anomaly profiles.

IV. Characterizing and fingerprinting: 1) petrologic studies to differentiate between marginal sea basalts and oceanic basalts; 2) sampling and characterization of remnant areas; 3) study of ancient examples of marginal seas.

V. Co-ordination: i.e. to integrate all of these studies on a regional basis.

Working Group I recommended also that a major research effort be undertaken during the 1980's to understand the origin, structure and composition of the poorly documented oceanic plateaus, which make up a significant part of the earth's crust.

\section{Physics and Chemistry of Magma Genesis}

The physical-chemical aspects of magma genesis in the upper mantle, their separation from source materials and subsequent ascent through the lithosphere - these topics were covered in the second part of the Conference. Discussions used experimental and theoretical data to point to the importance of vapors in producing cracks through which the magma moves upwards. Accordingly, experimental determination of density and viscosity is relevant to the study of structural states of magmatic melts to determine their movement and aggregation.

Many papers dealt with magma generation in the island arcs. Experimental data were presented to support the proposal that some Mg-rich calc-alkalic andesites of island arcs were formed by partial melting of the upper mantle lherzolite under hydrous conditions. In addition, geochemical evidence supports a model whereby fractional crystallization of basaltic magma can also produce calc-alkalic andesites, while some field evidence indicates another possibility of generating andesitic magma - by the mixing of two kinds of magmas; in short, it now seems that there are "andesites" and "andesites".
Systematic studies on the arc-trench systems, such as Papua New Guinea, indicate that there are several exceptions to the generalized model of magmatic evolution of $\mathrm{K}_{2} \mathrm{O} / \mathrm{SiO}_{2} /$ depth-to-Benioff-zone $(\mathrm{K}-\mathrm{h})$ relationship and to the sequence --- of tholeiitic to calc-alkalic to shoshonitic. Studies on the mafic and ultramafic xenoliths obtained from the basement also shed much light on the composition of the upper mantle and the lower crust under island arcs. Four papers on nephelinite magmatism discussed the generation and differentiation of these magmas. Major and minor element geochemistry of various types of rocks was presented by different institutions pointing out the importance of isotopic compositions and REE contents for discriminating the origin among various types of magmas.

Four of the papers studied the partitioning of some elements, especially $\mathrm{Mg}: \mathrm{Fe}$, among various synthetic mineral phases, pointing to the importance in estimating the physical conditions of magma genesis. The significance of $\mathrm{CO}_{2}$ and $\mathrm{H}_{2} \mathrm{O}$ in the generation of various types of magma, including carbonatite, at a subduction zone or the low velocity zone, was reviewed in light of the experimental evidence.

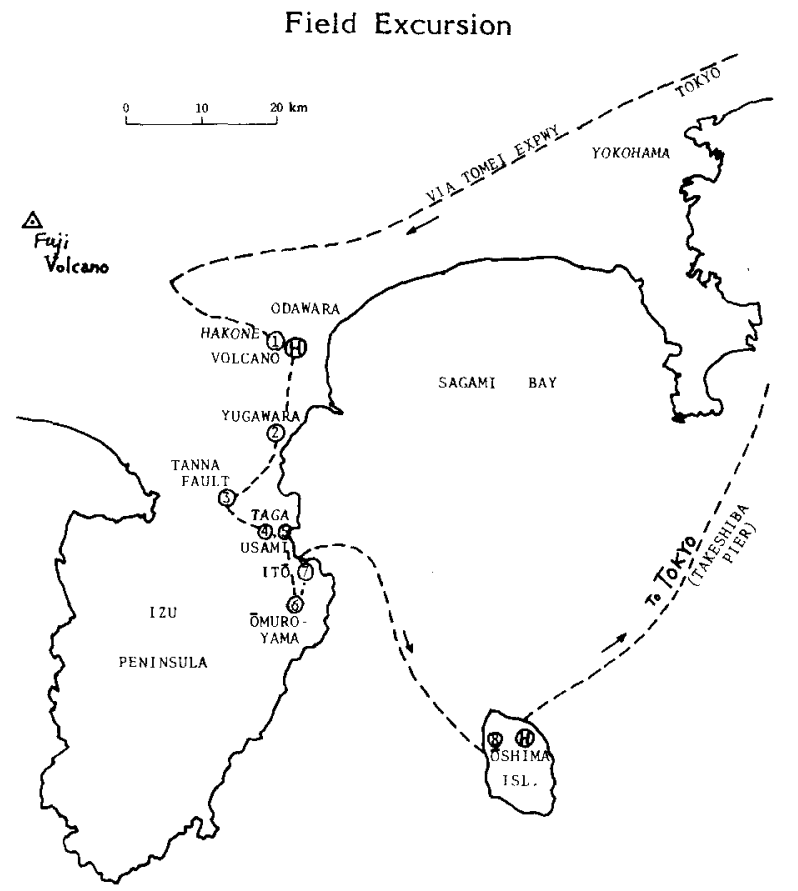

Map showing route of the field excursion.

Following the scientific sessions, a three-day field excursion to the Izu-Hakone District and Oshima Island was held to study some of the typical volcanoes in this region. The 50 foreign scientists and 20 Japanese participants were guided by Shigeo Aramaki of the University of Tokyo and Yasue Ohki of the Hot Spring Research Institute of Kanagawa Prefecture.

The first day was spent examining the magnificently exposed Hakone Caldera, particularly the flows (including three-pyroxene andesite), the central core, and the fumarolic activity.

Following an examination of the Sukumoyama area (high-alumina basalt), the Omuroyama pyroclastic cone 
and Tanna fault (re-activated in 1930), the party left Ito harbour by boat to Oshima Island. At the caldera rim of the Oshima volcano, the excellent view of the caldera rim and floor, and post-caldera cone, Mihara-yama, provided a perspective for studying the low temperature pyroclastic flows, the ragged 1950-51 lava field, and the agglutinate cone 1777-78 of Mihara-yama. Around the pit crater, about $200 \mathrm{~m}$ in depth, there are numerous concentric normal faults on the crater floor, along which steam escapes. Various types of lavas and ejecta of the 1950-51 and 1974 eruptions were examined and collected.

On the third day the participants had a splendid view of all the volcanoes of Isu Peninsula, including Fuji above the Sagami Bay. At midslope of the Oshima volcano, a road-cut displayed various air-fall ash and lapilli beds deposited around 700 A.D.

The highlight of the excursion was the spectacular exposure in a high road-cut, showing alternate layers of air-fall ash (due to violent explosive activity) and overlying soils representing a total time interval of about 15,000 years (see Cover Photo).

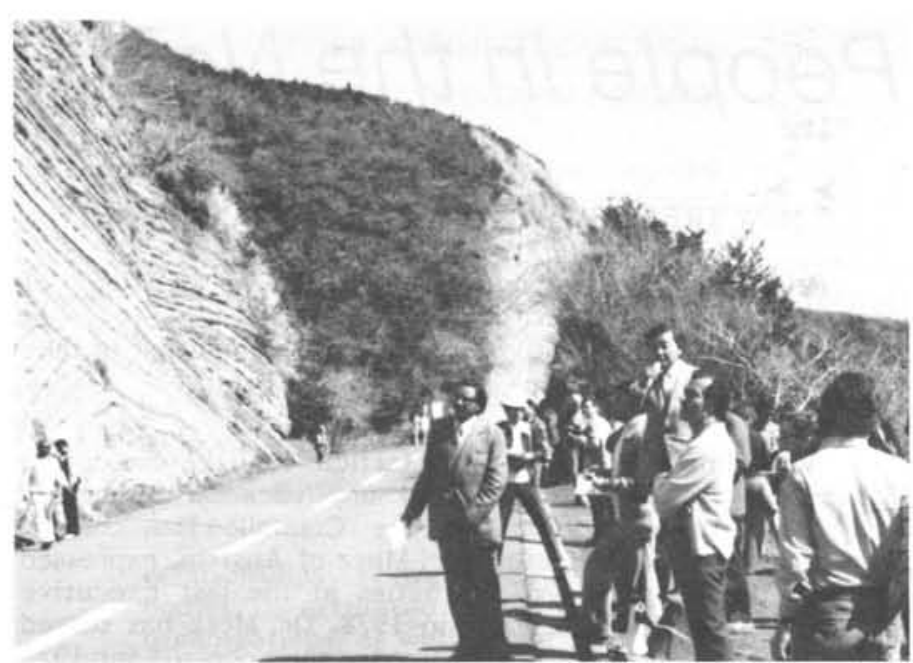

Field excursion participants examine the road-cut (front cover) exposing alternate layers of air-fall ashes at Oshima Volcano, while Professor Aramaki, Leader of the Excursion (centre) provides a commentary.

\section{anabababababababababab}

ABOUT THE AUTHOR: Recently named Professor Emeritus of Hokkaido University, Sapporo, Japan where he served as Professor in the Department of Geology and Mineralogy from 1962 to his retirement in April of this year, Professor Yagi is a Past-President of both the Japanese Association of Mineralogists, Petrologists and Economic Geologists, and the Volcanological Society of Japan. He has been a member of IUGS' Commission on Experimental Petrology at High Pressures and Temperatures since its inception in 1972. 